Çukurova Üniversitesi Mühendislik Mimarlık Fakültesi Dergisi, 35(2), ss. 413-423, Haziran 2020

Çukurova University Journal of the Faculty of Engineering and Architecture, 35(2), pp. 413-423, June 2020

\title{
Zamanla Sinüzoidal Olarak Değișen Manyetik Alan Şiddetinin Ters Basamak Geometrisinde Akış Ayrılması ve Isı Transferine Etkisi
}

\author{
Harun ZONTUL ${ }^{1}$, Beşir ŞAHIN*1 \\ ${ }^{\text {I}}$ Cukurova Üniversitesi, Mühendislik Fakültesi, Makina Mühendisliği Bölümü, Adana
}

Geliş tarihi: $03.06 .2020 \quad$ Kabul tarihi: 30.07 .2020

$\ddot{\mathbf{O z}}$

\begin{abstract}
Akış ayrılması, aerodinamik ve 1sı transferi uygulamalarında performansı büyük ölçüde etkileyen, tasarım sırasında göz ardı edilemeyecek fiziksel bir olgudur. Ters basamak geometrisi, akış ayrılmasını incelemek veya ayrılmış akışı manipüle etmeyi hedefleyen kontrol yöntemlerinin etkinliğini araştırmak amacıyla gerçekleştirilen çalışmalarda önemli bir yere sahip referans geometridir. Bu çalışmada bir aktif akış kontrol yöntemi olan manyetik alanın ters basamak geometrisinde akış ayrılması ve 1sı transferine etkisi sayısal olarak incelenmiştir. Manyetik alanın şiddeti zamana göre sinüzoidal bir fonksiyona bağlı kalarak sürekli şekilde değiştirilmiş̧ir. İnceleme laminer akış koşulları ile sınırlandırılmıştır. Çalışma sıvısı olarak su bazlı demir oksit $\left(\mathrm{Fe}_{3} \mathrm{O}_{4}\right.$-su) nano akışkanı kullanılmış ve nano akışkan tek fazlı olarak modellenmiştir. Sayısal simülasyonlar sonucunda incelenen yöntemin ölü akış bölgesine ve bu bölgedeki akışın sebep olduğu konveksiyon ile 1sı transferine etki etmede başarılı olduğu görülmüştür.
\end{abstract}

Anahtar Kelimeler: Akış kontrol yöntemleri, Akış ayrılması, Isı transferi, Manyetohidrodinamik, Ters basamak geometrisi

\section{The Effect of Sinusoidally Changing Magnetic Field Strength on Flow Separation and Heat Transfer in Backward-Facing Step Geometry}

\begin{abstract}
Flow separation is a physical phenomenon that greatly affects the performance in aerodynamic and heat transfer applications and cannot be neglected during design. Backward-facing step is the reference geometry, which is important in the studies carried out to examine the flow separation or to investigate the effectiveness of control methods aimed at manipulating the separated flow. In this study, the effect of the magnetic field, which is an active flow control method, on flow separation in backward-facing step geometry and heat transfer were investigated numerically. The intensity of the magnetic field was changed continuously, depending on a sinusoidal function over time. The investigation was limited to laminer flow conditions. Water based iron oxide (Fe3O4 - water) nanofluid was used as a working fluid and the nanofluid modeled as a single phase. As a result of numerical simulations, the method examined has been found to be successful in influencing the wake flow and the convective heat transfer caused by the flow in this zone.
\end{abstract}

Keywords: Backward-facing step, Flow control methods, Flow seperation, Heat transfer, Magnetohydrodynamics

*Sorumlu yazar (Corresponding author): Beşir ŞAHIIN, bsahin@cu.edu.tr 


\section{GIiRIŞ}

Akış ayrılması ya da sınır tabaka ayrılması olarak bilinen olgu aerodinamikde kaldırma kuvvetini azaltması ve sürtünme katsayısını artırması, 1s1 transferi uygulamalarında taşınımla 1sı transferini olumsuz etkileyebilmesi gibi nedenlerden ötürü mühendislikte önemli bir yere sahiptir. Bu olgunun pratikteki önemi nedeniyle ayrılmanın önlenmesi, geciktirilmesi ya da ayrılmış akışın tekrar yüzeye birleştirilmesine yönelik birçok araştırma mevcuttur. Ters basamak geometrisi bu araştırmalarda sıklıkça kullanılan referans geometridir. $\mathrm{Bu}$ geometride ayrılmış akışın tekrar yüzeye birleştiği noktanın basamağa olan uzaklığı ya da bir başka deyişle ölü akış bölgesinin büyüklüğü, basamak yüksekliği ve Reynolds sayısı parametrelerine bağlıdır [1-3].

Reynolds sayısı ve basamak yüksekliğinden bağımsız olarak ölü akış bölesine etki etmeyi amaçlayan aktif ve pasif akış kontrol yöntemleri de mevcuttur. Bu amaçla Chun ve Sung [4] ayrılma çizgisinin yakınındaki ince bir yarıktan sinüzoidal olarak salınan jet akışı göndermişler ve belirli salınım frekans ve genlik değerlerinde yeniden birleşme mesafesinde azalma elde etmişlerdir. Kanal üst duvarına yerleştirilen engel vasıtası ile ayrılmış akışı ölü akış bölgesini küçültecek şekilde yönlendirmenin alt duvardan 1sı transferini artırıcı sonuçlar doğurduğunu gösteren çalışmalar mevcuttur [5-8]. Cheng ve Tsay [9] üst duvara yerleştirilen engeller üzerine eklenen değişik ölçülerde yarıkların 1Sı transferi artışını olumsuz etkilemesine karşın basınç kaybını azalttığını belirtmiştir. Uruba ve arkadaşları [10] ölü ak1ş bölgesine ardışık emme ve üfleme yöntemi ile müdahalenin etkisini incelemişler, bu yöntemin yeniden birleşme mesafesini kısalttığını ancak emme/üfleme işlemleri için kullanılan ekstra enerji talebinin yüksek olduğuna dikkat çekmişlerdir. Bir aktif akış kontrol yöntemi olarak kanal girişinde salınımlı akış koşullarının uygulanması 1sı transferi uygulamalarında etkili olabildiği bilinmektedir, bu yöntemin ters basamak geometrisinde 1S1 transferine olumlu katkısı olduğunu gösteren çalışmalar da vardır [11-13]. Tihon ve arkadaşları [14] laminerden türbülansa geçiş koşullarında salınımlı akışın optimum frekans değeri için yeniden birleşme mesafesini yüzde seksen kadar azaldığını tespit etmişlerdir. Ayrıca Selimefendigil ve Öztop [15] salınımlı akışa ek olarak basamak sonrasındaki alt duvarın oluklu olduğu bir geometri için sayısal inceleme gerçekleştirmişlerdir. Akışın manyetik alan vasıtası ile manipüle edilmesi özellikle son yıllarda araştırmacıların dikkatini çeken bir yöntemdir. Abbassi ve Nassrallah [16] akış yönünün normali doğrultusunda manyetik alan etkiyen bir durumu nümerik olarak simüle ederek manyetik alanın yeniden birleşme mesafesini kısaltıcı etki yarattığını göstermişlerdir. Selimefendigil ve Öztop [17] manyetik alanı belirli açılarda uygulayarak düşük Reynolds sayılarında akış ayrılmasını önlemede oldukça başarılı sonuçlar elde etmişlerdir. Kanal içerisine silindir yerleştirerek ölü akışın bulunduğu bölgeden gerçekleşen 1sı transferinde önemli ölçüde artış elde edilebileceğini gösteren çalışmalar mevcuttur $[18,19]$. Selimefendigil ve Öztop [20,21] silindiri döndürerek belirli dönüş yönleri ve hızları için durağan halden daha iyi 1sı transferi sağladığını belirtmiştir. Chan ve Lien [22] basamaktan ayrılan akışı gözenekli ortamdan geçirerek akış ayrılmasına müdahale etmişler ve düşük geçirgenlikteki gözenekli ortamların ölü akış bölgesini elimine etmekte daha başarılı sonuç verdiğini rapor etmişlerdir. Plazma aktüatörleri akış ayrılmasını kontrol etmede etkili bir yöntemdir, bu yöntemin ters basamak geometrisindeki performansını inceleyen deneysel çalışmalar mevcuttur [23-27]. Inaoka ve arkadaşları [28] basamak üzerine yerleştirdiği elektromanyetik aktüatörlü kanatlara salınım hareketi vermek suretiyle alt duvardan gerçekleşen 1S1 transferini iyileştirmiştir. Yukarıdaki literatür araştırmasında ters basamak geometrisinde ayrılmış akışı kontrol etmeye yönelik kullanılmış yöntemler özetlenmiştir. $\mathrm{Bu}$ çalışmada kontrol yöntemi olarak manyetik alan seçilmiş ancak manyetik alan şiddeti sabit tutulmayıp zamanla sinüzoidal olarak değiştirilmiştir. Yöntemin etkinliği sayısal simülasyonlardan elde edilen 1S1 transferi ve akış karakteristiği sonuçları ile ortaya koyulmuştur. 


\section{PROBLEM TANIMI}

Bu çalışmada içerisinde ters basamak geometrisi bulunduran bir kanaldaki akış ve kanal alt duvarı ve basamak dikey duvarından gerçekleşen konveksiyonla 1sı transferi problemi incelenmiştir. Şekil 1'de şematik olarak gösterildiği üzere basamak yüksekliği kanal yüksekliğinin yarısıdır. Akışkan olarak su bazlı $\mathrm{Fe}_{3} \mathrm{O}_{4}$ nano akışkanı seçilmiştir ve akışkanın termofiziksel özelliklerinin sıcaklıkla değişmediği kabul edilmiş ancak karışık konveksiyonun mevcut olması nedeniyle yönetici denklemlerdeki efektif yoğunluk Boussinesq yaklaşımı ile hesaplanmıştır. Ayrıca 1şınımla 1s1 transferi etkileri ihmal edilmiş, akışın iki boyutlu ve laminer olduğu kabulü yapılmıştır. Tüm bu koşullar altında yönetici denklemler aşağıdaki formda olmaktadır:

Süreklilik denklemi (Eşitlik 1):

$\frac{\partial \mathrm{U}}{\partial \mathrm{X}}+\frac{\partial \mathrm{U}}{\partial \mathrm{Y}}=0$

$\mathrm{X}$ yönü için momentum denklemi (Eşitlik 2):

$$
\begin{aligned}
& \frac{\partial \mathrm{U}}{\partial \lambda}+\mathrm{U} \frac{\partial \mathrm{U}}{\partial \mathrm{X}}+\mathrm{V} \frac{\partial \mathrm{U}}{\partial \mathrm{Y}}=-\frac{\rho_{\mathrm{f}}}{\rho_{\mathrm{nf}}} \frac{\partial \mathrm{P}}{\partial \mathrm{X}}+ \\
& \frac{1}{\operatorname{Re}}\left(\frac{\partial^{2} \mathrm{U}}{\partial \mathrm{X}^{2}}+\frac{\partial^{2} \mathrm{U}}{\partial \mathrm{Y}^{2}}\right)+\frac{\rho_{\mathrm{bf}}}{\rho_{\mathrm{nf}}} \frac{\sigma_{\mathrm{bf}}}{\sigma_{\mathrm{nf}}} \frac{\mathrm{Ha}^{2}}{\operatorname{Re}}\left(\sin ^{2}(2 \pi \lambda)\right)
\end{aligned}
$$

Y yönü için momentum denklemi (Eşitlik 3):

$$
\begin{aligned}
& \frac{\partial \mathrm{V}}{\partial \lambda}+\mathrm{U} \frac{\partial \mathrm{V}}{\partial \mathrm{X}}+\mathrm{V} \frac{\partial \mathrm{V}}{\partial \mathrm{Y}}=-\frac{\rho_{\mathrm{f}}}{\rho_{\mathrm{nf}}} \frac{\partial \mathrm{P}}{\partial \mathrm{X}}+ \\
& \frac{1}{\operatorname{Re}}\left(\frac{\partial^{2} \mathrm{~V}}{\partial \mathrm{X}^{2}}+\frac{\partial^{2} \mathrm{~V}}{\partial \mathrm{Y}^{2}}\right)+\theta \frac{\mathrm{Gr}}{\mathrm{Re}^{2}}
\end{aligned}
$$

Enerji denklemi (Eşitlik 4):

$$
\begin{aligned}
& \frac{\partial \theta}{\partial \lambda}+U \frac{\partial \theta}{\partial X}+V \frac{\partial \theta}{\partial Y}= \\
& -\frac{1}{\operatorname{RePr}} \frac{k_{n f}}{k_{b f}}+\left(\frac{\partial^{2} \theta}{\partial X^{2}}+\frac{\partial^{2} \theta}{\partial Y^{2}}\right)
\end{aligned}
$$

$(\rho \beta)_{\mathrm{nf}}=(1-\varnothing)(\rho \beta)_{\mathrm{bf}}+\emptyset(\rho \beta)_{\mathrm{np}}$

$\mu_{\mathrm{nf}}=\frac{\mu_{\mathrm{bf}}}{(1-\varnothing)^{2.5}}$

$\rho_{\mathrm{nf}}=(1-\varnothing) \rho_{\mathrm{bf}}+\varnothing \rho_{\mathrm{np}}$

$\left(\rho c_{p}\right)_{n f}=(1-\varnothing)\left(\rho C_{p}\right)_{b f}+\varnothing\left(\rho C_{p}\right)_{p}$

$\frac{\mathrm{k}_{\mathrm{nf}}}{\mathrm{k}_{\mathrm{bf}}}=\frac{\left(\mathrm{k}_{\mathrm{np}}+2 \mathrm{k}_{\mathrm{bf}}\right)-2 \varnothing\left(\mathrm{k}_{\mathrm{bf}}-2 \mathrm{k}_{\mathrm{np}}\right)}{\left(\mathrm{k}_{\mathrm{np}}+2 \mathrm{k}_{\mathrm{bf}}\right)+\emptyset\left(\mathrm{k}_{\mathrm{bf}}-\mathrm{k}_{\mathrm{np}}\right)}$

$\sigma_{\mathrm{nf}}=\sigma_{\mathrm{bf}}\left(1+\frac{3\left(\sigma_{\mathrm{np}} / \sigma_{\mathrm{bf}}-1\right) \emptyset}{\left(\sigma_{\mathrm{np}} / \sigma_{\mathrm{bf}}+2\right)-\left(\left(\sigma_{\mathrm{np}} / \sigma_{\mathrm{bf}}-1\right) \emptyset\right.}\right)$ 
Zamanla Sinüzoidal Olarak Değişen Manyetik Alan Şiddetinin Ters Basamak Geometrisinde Akış Ayrılması ve Isı Transferine Etkisi

$\alpha_{\mathrm{nf}}=\frac{\mathrm{k}_{\mathrm{nf}}}{\left(\rho \mathrm{C}_{\mathrm{p}}\right)_{\mathrm{nf}}}$

Yukarıda verilen dinamik viskozite, $\mu$ 1sı iletim katsayısı $\mathrm{k}$ ve elektrik iletkenliği, $\sigma$ terimlerinin hesaplanması için kullanılan 9, 10 ve 11 numaralı eşitlikler sırasıyla Brinkman [29], Maxwell-Garnet [30] ve Maxwell [31] modellerinden alınmıştır. Isıtılan yüzeylerden meydana gelen isı transferinin miktarı Nusselt sayısı, $\mathrm{Nu}$ hesaplanarak belirlenmiştir.

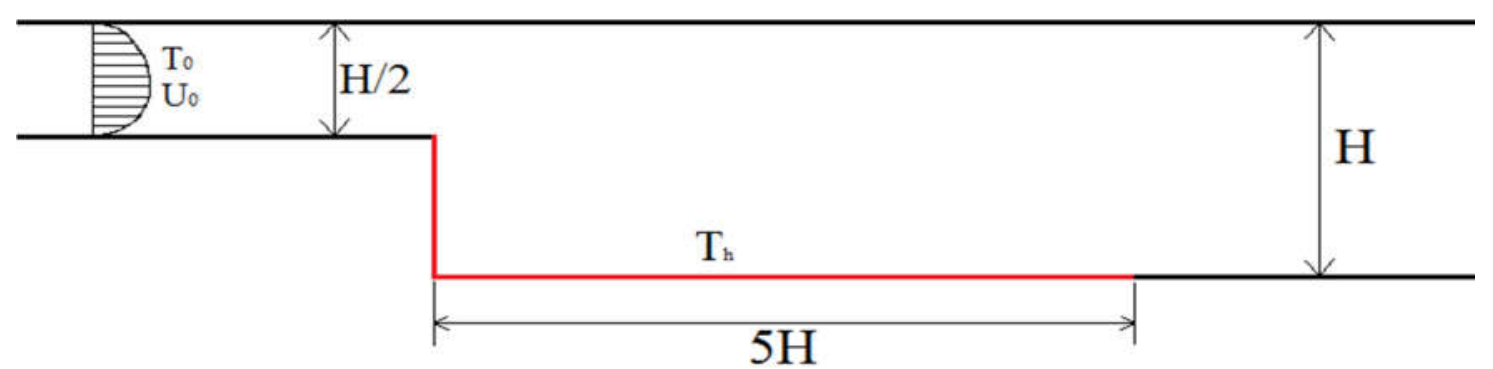

Şekil 1. Problem geometrisinin şematik gösterimi

Çizelge 1. Nano-partikül ve suyun özellikleri

\begin{tabular}{cccccc}
\hline & $\rho\left(\mathrm{kg} / \mathrm{m}^{3}\right)$ & $\mathrm{Cp}(\mathrm{J} / \mathrm{kg} \mathrm{K})$ & $\mathrm{k}(\mathrm{W} / \mathrm{m} \mathrm{K})$ & $\beta\left(\mathrm{K}^{-1}\right)$ & $\sigma$ \\
\hline $\mathrm{Su}$ & 997.1 & 4179 & 0.613 & $21 \times 10^{-4}$ & 0.05 \\
\hline $\mathrm{Fe}_{3} \mathrm{O}_{4}$ & 5200 & 670 & 6 & $1.3 \times 10^{-5}$ & 2500 \\
\hline
\end{tabular}

Yerel Nusselt sayısı (Eşitlik 13):

$\dot{\mathrm{Nu}}=-\frac{\mathrm{k}_{\mathrm{nf}}}{\mathrm{k}_{\mathrm{bf}}} \frac{\dot{\mathrm{q}}}{\left(\theta_{\mathrm{h}}-\theta_{0}\right)} \mathrm{H}$

Ortalama Nusselt sayısı (Eşitlik 14):

$\overline{\mathrm{Nu}}=\frac{1}{5 \mathrm{H}} \int_{0}^{5 \mathrm{H}} \dot{\mathrm{Nu}} \mathrm{dX}$

Zaman ortalamalı Nusselt sayısı (Eşitlik 15):

$\mathrm{Nu}=\frac{1}{\lambda} \int_{0}^{\lambda} \mathrm{Nu} \mathrm{d} \lambda$

\section{3. ÇÖZÜM YÖNTEMI DOĞRULAMA}

Önceki bölümde tanımlanmış olan problem Ansys Fluent Hesaplamalı Akışkanlar Dinamiği paket programı kullanılarak sayısal olarak çözülmüştür. Akış alanına etki ettirilen manyetik alan Fluent yazılımının Kullanıcı Tanımlı İşlev (User Defined Function) özelliği vasıtasıyla uygulanmıştır.
Basınç ve hız alanlarının birleştirilmesi için Patankar'ın SIMPLE algoritması kullanılmıştır. Mekansal ayrıklaştırmadaki gradyen terimleri için hücre tabanlı en küçük kareler yöntemi seçilmiştir. Ayrıca Eşitlik 1-4 ikinci dereceden Upwind yöntemi kullanılarak ayrıklaştırılmıştır. Her bir zaman adımı için itersayonlar süreklilik ve momentum denklemi için $10^{-5}$, enerji denklemi için $10^{-6}$, yakınsama kriterine ulaşılana kadar devam ettirilmiştir. Simülasyon ise sicak yüzeydeki Nusselt sayısının zamanla değişimi periyodik olana kadar sürdürülmüştür. Ayrıklaştırma işlemi için gerekli olan ağdaki eleman sayısının çözüme etkisini gidermek amacıyla farklı sayılarda dikdörtgensel eleman bulunduran dört adet ağ yapısı test edilmiştir. Maksimum eleman boyutu ve toplam eleman sayıları Çizelge 1'de verilen ağ yapıları için gerçekleştirilen simülasyonlar sonucu Nusselt sayısının 1sıtılan alt duvar boyunca değişimini gösteren grafik Şekil 2'de gösterilmiş. Bu şekilden de görülebileceği gibi seyrek yapıdaki Ağ 1'den 
daha sık yapıdaki Ağ 4'e doğru ağdaki eleman sayısı arttıkça Nusselt sayısının dağılımında değişimler oluşmaktadır. Ancak Ağ 3 ile A $\breve{g} 4$ karşılaştırdığında bu iki yapının sonuçlara olan etkisinin birbirine benzer olduğu görülmektedir. $\mathrm{Bu}$ nedenle Ağ 3 olarak adlandırılan yapının yeterince doğru sonuçlar verdiği anlaşıldığından çözüm süresini uzatmamak adına eleman sayısı daha da artırılmamış, tüm simülasyonlar için Ağ 3 adlı ağ yapısı kullanılmıştır.
Çizelge 2. Ağdan bağımsızlaştırma testi için kullanılan eleman sayıları

\begin{tabular}{|c|c|c|}
\hline $\begin{array}{c}\text { Maks. Eleman Boyutu } \\
(\mathrm{mm})\end{array}$ & $\begin{array}{c}\text { Eleman } \\
\text { Say1s1 }\end{array}$ & \\
\hline 0,005 & 23702 & $\mathrm{~A} \breve{g} 1$ \\
\hline 0,003 & 53008 & $\mathrm{~A} \breve{g} 2$ \\
\hline 0,001 & 402621 & $\mathrm{~A} \breve{g} 3$ \\
\hline 0,0009 & 483952 & $\mathrm{~A} \breve{g} 4$ \\
\hline
\end{tabular}

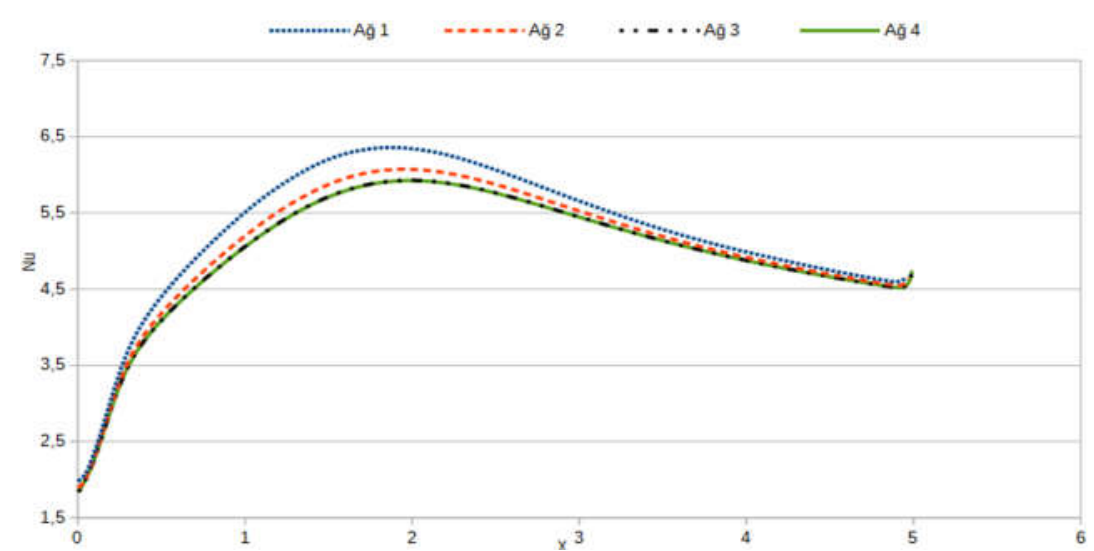

Şekil 2. Ağgdaki farklı eleman sayılarının Nusselt sayısı dağılımına etkisi

Çözüm prosedürü, doğrulama amacıyla Tsay ve arkadaşları [5]'nın çalışmasında tanımlanan ters basamak geometrisi üzerinden akış ve 1sı transferi problemine uygulanmıştır. Doğrulama için seçilen durumda Reyolds sayısı 500, Prandtl sayıs1 0,7'dir ve kanal üst duvarında herhangi bir engel bulunmamaktadır. Nusselt sayısının 1sitılan alt duvar boyunca dağılımı grafiğe döküldüğünde (Şekil 3) mevcut prosedürün Tsay ve arkadaşları [5] tarafindan elde edilen verilerle oldukça uyumlu sonuçlar ürettiği görülmektedir.

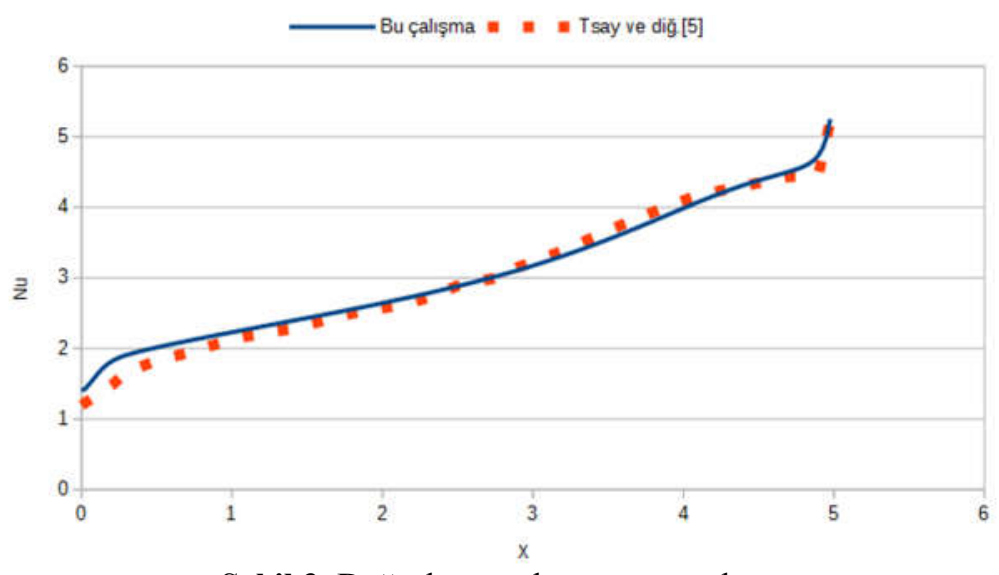

Şekil 3. Doğrulama çalışması sonuçları 


\section{BULGULAR VE TARTIŞMA}

Şiddeti zamanla sinüzoidal olarak değişen manyetik alanın, akış üzerindeki etkisini gösterebilmek için Şekil 4'de zaman ortalamalı akım çizgileri ve hız konturları gösterilmiştir. Şekilde incelenen durum için Reynolds sayısı değeri 100, nano-akışkanın partikül oranı $\% 2$ 'dir, $\phi=0,02$. Manyetik alanın olmadığı bir başka deyişle Hartman sayısının sıfır olduğu koşul ile üç farklı manyetik alan şiddetinin etki ettirildiği durumlar karşılaştırılmıştır. Manyetik alanın etki etmediği durumda standart bir ters basamak geometrisi üzerinden akışta olması beklendiği gibi basamağı terk eden ana akım katı yüzeyden ayrılmakta ve belirli bir mesafe katettikten sonra tekrar yüzeyle birleşmektedir. Şekilden de görüleceği gibi basamağın dikey duvarı ile ana akımın tekrar yüzeye birleştiği noktaya kadar olan bölgede ölü akış bölgesi olarak da adlandırılan ikincil akım bölgesi oluşmaktadır. Hız konturu değerlerine baktığımızda ölü akış bölgesinde hızın ana akımdan belirgin şekilde düşük olduğu görülmektedir. Hartman sayısının değeri 10 olarak belirlendiğinde manyetik alanın ortaya çıkardığ1 Lorentz kuvvetlerinin akış alanı üzerinde etkisi kısıtlı olmaktadır. Bu Hartman sayısı değerinde hız konturları ölü akış bölgesinde bir hız artışına işaret ediyor olsa da manyetik alanın asıl etkisi Hartman sayısının 20 olduğu durum için görülmektedir. Bu koşulda şekilden de görüleceği gibi kanalın üst duvarında ikinci bir sirkülasyon bölgesi oluşmaktadır. Yeni durumda oluşan bu ikinci sirkülasyon bölgesi ana akımı aşağı doğru baskılamakta ve daha dar bir kesitten geçmeye zorlamaktadir. Bunun sonucunda hiz konturu değerlerinin de gösterdiği gibi ölü akış bölgesinde önceki duruma göre daha belirgin bir hız artışı gözlemlenmektedir. Hartman sayısı 30 olduğunda manyetik alanın akış üzerindeki etkisi daha agresif hale gelmiştir. Kanal üst duvarında oluşan sirkülasyon bölgesi genişleyerek ana akımı baskılama etkisini artırmıştır ve böylece ölü akış bölgesi de baskılanarak küçülmüş, ana akımın yüzeye tekrar birleşme mesafesi kısalmıştır. Ayrıca, hem sirkülasyon bölgelerinde hem de arasında kalan ana akımda bariz hız artışı gözlemlenmiştir.

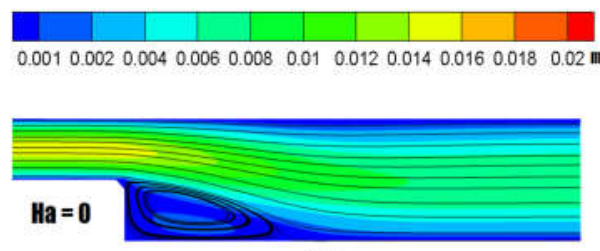

(a)

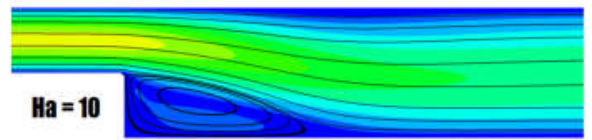

(b)

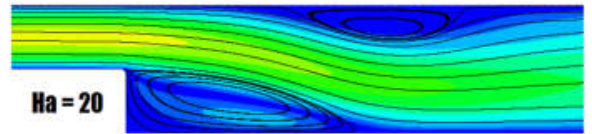

(c)

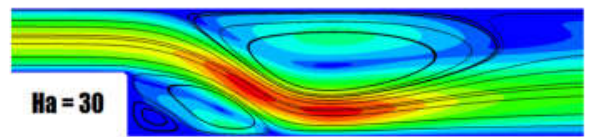

(d)

Şekil 4. $\mathrm{Re}=100, \phi=0,02, \mathrm{Gr} / \mathrm{Re}^{2}=1$ değerleri için farklı manyetik alan şiddetlerinin akışa etkisi 
Şekil 4'deki her bir koşulun basamak dikey duvarı ve kanal alt duvarından meydana gelen 1S1 transferine etkisi zaman ortalamal yerel Nusselt sayısının dağılımı verilerek Şekil 5'de gösterilmiştir. $\mathrm{Ha}=0$ ve $\mathrm{Ha}=10$ değerleri için akış alanında önemli bir değişiklik meydana gelmemesinden de bekleneceği üzere bu iki durum için Nusselt sayısının alt duvar boyunca dağılımında kayda değer bir farklılık oluşmamıştır. $\mathrm{Ha}=20$ olduğunda Nusselt sayısı $\mathrm{X} \leq 2$ 'de manyetik alanın olmadığı duruma yakın seyretmekte ancak sonrasında 1S1 transferinin bir miktar arttı̆ 1 görülmektedir. X'in 2'den az olduğu yerde manyetik alanın sirkülasyon bölgesindeki hıza bir etkisi olmaması nedeniyle böyle bir sonuç ortaya çıkmıştır. Manyetik alanın akış üzerinde en büyük etkiyi yarattığ $\mathrm{Ha}=30$ değerinde $1 \mathrm{~s} 1$ transferi sonuçlarının oldukça yüksek çıktığı görülmektedir. $\mathrm{X}<1$ ile sınırlı kalan düşük hızlı ölü akış bölgesinde 1sı transferi önceki durumlar ile benzer seyretmiş ancak akış hızının Şekil 4(d)'de görüldüğü gibi yüksek seyrettiği sirkülasyon bölgesinde Nusselt sayısı yükselerek maksimum değerine ulaşmıştır. Sonrasında 1sıl gelişmişlik koşullarına yaklaşıldıkça beklendiği üzere 1s1 transferi değeri azalarak yatay seyir izlemiştir. Koşulların ısıl olarak gelişmeye başladığı bölgede dahi ana akımın alt duvara baskılanması ve akışın diğer durumlara göre daha erken yüzeye birleşmesi nedeniyle 1sitılan duvara yakın bölgede hiz gradyeni ve dolayısıyla ısı transferi, diğer Hartman sayılarındaki durumlara göre yüksek olmaktadır.

Şekil 5(b)'de Hartman sayısının basamak dikey duvarından 1s1 transferine etkisi gösterilmiştir. İncelenen Hartman sayıları içerisinde yalnızca $\mathrm{Ha}=30$ değerinde dikey duvardan 1sı transferi artış1 yaşanmıştır. Basamak dikey duvarı yalnızca ölü akışın domine ettiği bölge ile temas etmektedir ve ancak manyetik alan yüksek Hartman sayıs1 değerinde bu bölgeye nufüz edebildiğinden is1 transferinde böyle bir sonuç ortaya çıkmaktadır.

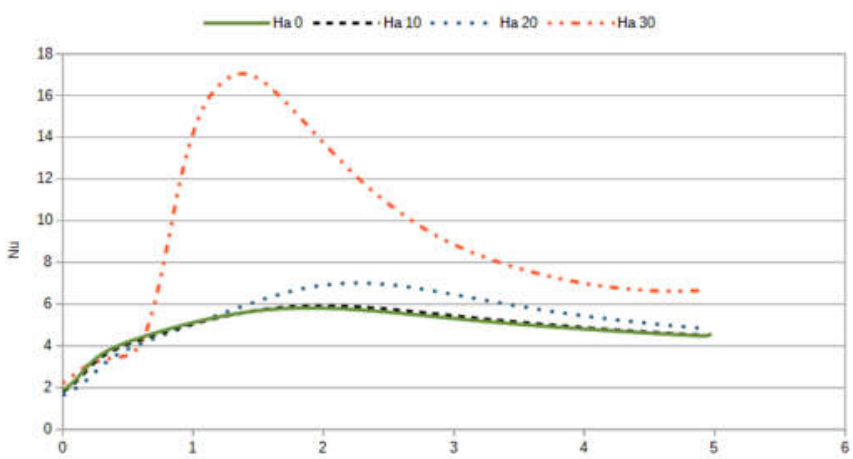

(a)

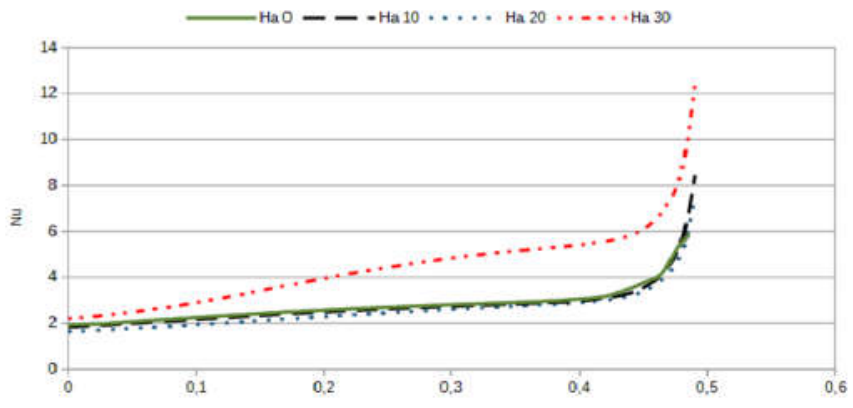

(b)

Şekil 5. Hartman sayısının $\mathrm{Re}=100, \phi=0,02, \mathrm{Gr} / \mathrm{Re}^{2}=1$ koşullarında (a) alt duvardan, (b) basamak dikey duvarından isı transferine etkisi 
Reynolds sayısı 200 olduğunda Şekil 6(a)'da görüldüğü gibi ölü akış bölgesi aşağı akım yönünde genişlemektedir. $\mathrm{Bu}$ Reynolds sayıs1 değerinde düşük manyetik alan şiddetinin $(\mathrm{Ha}=10)$ akış üzerinde hissedilebilir bir etkisi olmamıştır. Hartman sayısının $\mathrm{Ha}=20$ olduğu durumda Şekil 4(c)'de görülen duruma benzer bir şekilde kanal üst duvarında ikinci bir sirkülasyon bölgesi oluşmaktadır. Oluşan ikinci sirkülasyon bölgesinin etkisiyle ana akım aşağı doğru yönlendirilmiş ve ölü akış bölgesindeki sirkülasyon hızının şiddetinde bir fark ortaya çıkmış olsa da bu manyetik alan şiddetinin ölü akış bölgesi büyüklüğünü azaltmada herhangi bir etkisi olmadığı görülmektedir. En yüksek Hartman sayısı değerinde üst duvar yakınında oluşan sirkülasyon bölgesinin genişlemesi neticesinde ölü akış bölgesinde küçülme meydana gelmektedir. Ancak ölü akış bölgesindeki bu küçülme Şekil 4(d)'de meydana gelene nispetle daha az olmuş, akışın yüzeye yeniden birleştiği nokta Reynolds sayısının 100 değerinde olduğu kadar öne çekilememiştir.
Reynolds sayısının 200 olması ile genişleyen ölü akış bölgesinin 1S1 transferi üzerindeki etkisi Şekil 7(a)'da verilen Nusselt sayısı dağılımlarında görülmektedir. Grafikten de görüleceği gibi tüm Hartman sayısı değerlerinde Nusselt sayısının maksimum yaptığ 1 nokta Reynolds 100'e göre daha ileridedir. Şekil 5(a)'da olduğu gibi $\mathrm{Ha}=10$ manyetik alanın etki etmediği duruma göre kayda değer bir avantaj sağlamamıştır. Hartman sayısı 20 değerinde Nusselt sayısının zirve yaptığ 1 nokta düşük Hartman sayılarındaki zirve noktalarından ayrışmakta sonrasında da 1sı transferi aşağı akım boyunca daha yüksek seyretmektedir. Maksimum 1S1 transferi artışı $\mathrm{Ha}=30$ değerinde elde edilmiştir ancak artışın aynı Hartman sayısı değerinde Reynolds 100 için gerçekleşen artıştan daha az olduğu dikkat çekmektedir. $\mathrm{Re}=200$ ' de manyetik alanın basamak dikey duvarından 1sı transferine önemli bir etkisi olmadığı görülmektedir (Şekil 5(b)). Yalnızca $\mathrm{Y}>0,3$ için $\mathrm{Ha}=30$ değerinde 1sı transferinde küçük bir atış olmasına karşın $\mathrm{Y}<0,3$ 'de $1 \mathrm{~s}$ ı transferi azalmıştır.

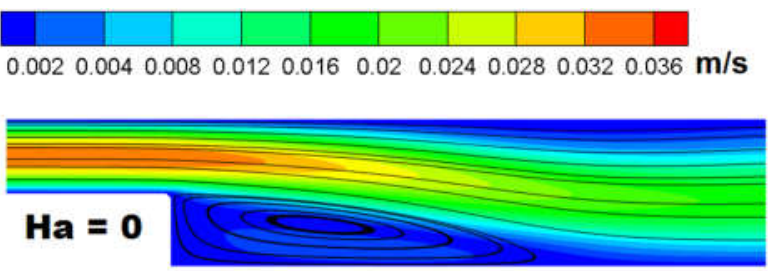

(a)

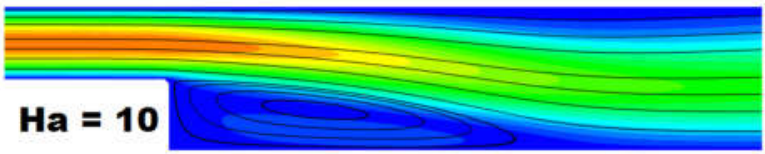

(b)

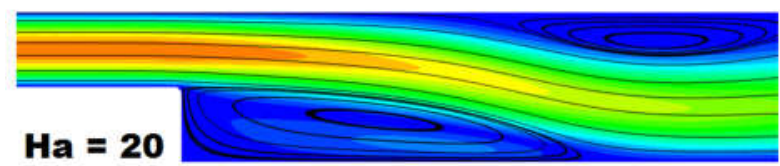

(c)

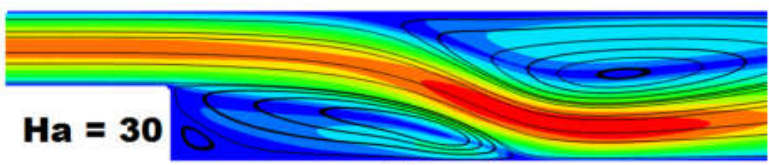

(d)

Şekil 6. $\mathrm{Re}=200, \phi=0,02, \mathrm{Gr} / \mathrm{Re}^{2}=1$ değerleri için farklı manyetik alan şiddetlerinin akışa etkisi 

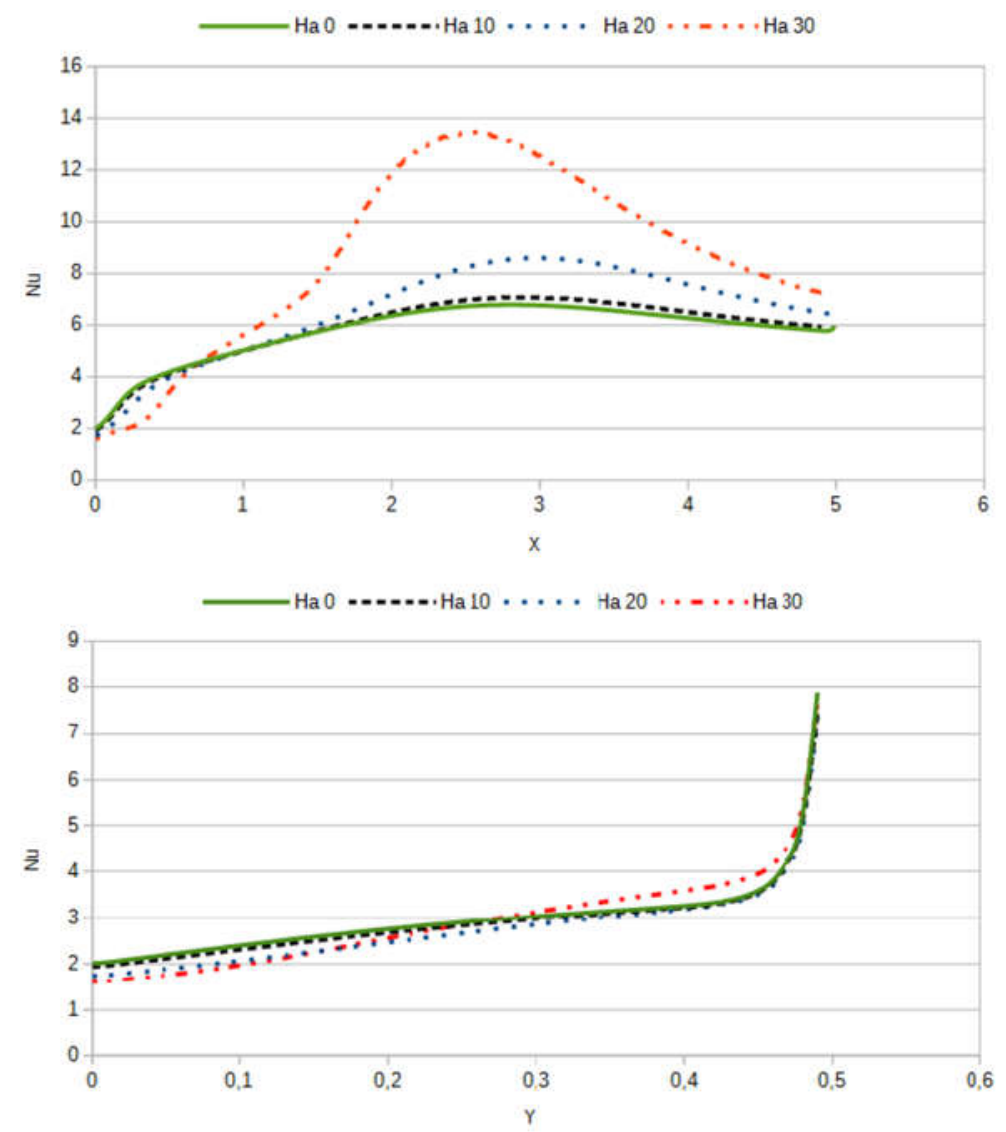

Şekil 7. Hartman sayısının $\operatorname{Re}=200, \phi=0,02, \mathrm{Gr} / \mathrm{Re}^{2}=1$ koşullarında (a) alt duvardan (b) basamak dikey duvarından isı transferine etkisi

Çizelge 3'de tüm Hartman sayılarında kanal alt duvarı boyunca ortalama Nusselt sayılarının manyetik alan etki etmediği durumdaki ortalama Nusselt sayılarına oranları verilmiştir. Değerlerden de anlaşılacağ gibi artan manyetik alan şiddeti 1sı transferine olumlu katk1 sağlamaktadır. İncelenen geometride manyetik alanın 1sı transferine katkıs1 iki şekilde olmaktadır; birinci etki sıcak duvarlar ile temas halinde bulunan bölgedeki akışın sirkülasyon hızını artırması, ikinci etki ise ölü akış bölgesini küçültmesidir.

Çizelge 3. Farklı manyetik alan şiddetlerinin 1s transferi artış oranları

\begin{tabular}{|l|c|c|c|}
\hline & Ha 10 & Ha 20 & Ha 30 \\
\hline Re 100 & 1,011 & 1,114 & 1,896 \\
\hline $\operatorname{Re} 200$ & 1,023 & 1,140 & 1,503 \\
\hline
\end{tabular}

Re 100 ve $\operatorname{Re} 200$ değerlerinde manyetik alanın 1S1 transferi artışına etkisi incelendiğinde Ha 10 ve Ha 20'de Re 200 için manyetik alanın Re 100'e göre daha iyi 1sı transferi artışı getirdiği görülmektedir. Ancak Ha 30 olduğunda durum tersine dönmüştür. Re 100 için elde edilen 1s1 transferi artışı $\operatorname{Re} 200$ 'de elde edilene oranla belirgin şekilde yüksektir. $\mathrm{Bu}$ durumun sebebi şöyle açıklanabilir; Ha 10 ve Ha 20 değerlerinde manyetik alanın ölü akış bölgesinin büyüklüğüne herhangi bir etkisi olmamaktadır. Bu manyetik alan şiddetlerinde 1sı transferi artışının temel sebebi sirkülasyon bölgesindeki hız artışıdır. Ancak Hartman sayısı 30 için ölü akış bölgesinin küçülmesinin de yarattığı etkinin 1 sı transferine katkısı bulunmaktadır. Şekil 4(d) ve Şekil 6(d) karşılaştırıldığında görüleceği üzere Re 200'de 
Zamanla Sinüzoidal Olarak Değişen Manyetik Alan Şiddetinin Ters Basamak Geometrisinde Aklş Ayrlması ve Isı Transferine Etkisi

manyetik alan ölü akış bölgesinin küçülmesi hususunda Re 100'de olduğu kadar etkili değildir. Bir başka deyişle manyetik alan nedeniyle ortaya çıkan Lorentz kuvvelerinin, büyük atalet kuvvetlerinin söz konusu olduğu yüksek Renolds sayısında etkisi azalmaktadır. Dolayısıyla küçülen ölü akış bölgesinin yarattığı etki Re 100'de daha fazla olduğundan 1sı transferi artışı da bu Reynolds sayısında daha iyi olmuştur.

\section{SONUÇLAR}

Ters basamak geometrisi üzerinden akışta şiddeti zamanla değişen manyetik alanın 1sı transferine etkisini incelemek amacıyla gerçekleştirilen sayısal simülasyonlar sonucunda Hartman sayısının 20 ve 30 olduğu durumlarda manyetik alanın akış üzerinde kayda değer etki yarattığ1 tespit edilmiștir. $\mathrm{Bu}$ Hartman sayılarında kanal üst duvarında yeni bir sirkülasyon bölgesi oluşmakta ve böylece ana akım aşağı baskılanmaktadır. Ancak bu baskılanmanın neticesi olarak ölü akış bölgesinin küçülmesi yalnızca Ha 30 olduğunda gerçekleşmektedir. İncelenen tüm Hartman sayılarında 1S1 transferinde artış görülmektedir ancak kayda değer artış $\mathrm{Ha}=30$ değerinde elde edilmiștir. $\mathrm{Re}=100$ ve $\mathrm{Re}=200$ 'de $\mathrm{Ha}=30$ için sırasıly $\% 90$ ve $\% 50$ 1sı transferi artışı söz konusudur. Düşük Reynolds sayısında atalet kuvvetleri daha az olduğu için manyetik alanın ortaya çıkardığı Lorentz kuvvetleri ölü akış bölgesinin baskılanmasında daha etkili olmuştur. Böylece $\mathrm{Re}=100$ 'de $\mathrm{Re}=200$ 'e göre daha yüksek artış elde edilmiştir.

\section{KAYNAKLAR}

1. Kim, J., Kline, S.J., Johnston, J.P., 1980. Investigation of a Reattaching Turbulent Shear Layer: Flow Over a Backward-facing Step. 302-308.

2. Armaly, B.F., Dursts, F., Pereira, J.C.F., Schonung, B., 1983. Experimental and Theoretical Investigation of Backward-facing Step Flow. Journal of Fluid Mechanics 127, 473-496.

3. Adams, E.W., Eaton, J.K., 1988. An LDA Study of the Backward-facing Step Flow,
Including the Effects of Velocity Bias, 275-282.

4. Chun, K.B., Sung, H.J., 1996. Control of Turbulent Separated Flow Over a Backwardfacing Step by Local Forcing, Experiments in Fluids, 21, 417-426.

5. Tsay, Y.L., Chang, T.S., Cheng, J.C., 2005. Heat Transfer Enhancement of Backwardfacing Step Flow in a Channel by Using Baffle Installation on the Channel Wall, Acta Mechanica, 174, 63-76.

6. Nie, Jian H., Chen, Y.T., Hsieh, H.T., 2009. Effects of a Baffle on Separated Convection Flow Adjacent to Backward-facing Step. International Journal of Thermal Sciences 48, 618-625.

7. Mohammed, Omer, H.A., Alawi, A., Wahid, M.A., 2015. Mixed Convective Nanofluid Flow in a Channel Having Backward-facing Step with a Baffle, Powder Technology, 275, 329-343.

8. Selimefendigil, F., Öztop, H.F., 2013. Numerical Analysis of Laminer Pulsating Flow at a Backward Facing Step with an Upper Wall Mounted Adiabatic Thin Fin, Computers \& Fluids 88, 93-107.

9. Cheng, J.C., Tsay, Y.L., 2006. Effects of Solid and Slotted Baffles on the Convection Characteristics of Backward-facing Step Flow in a Channel, Heat and Mass Transfer, 42(9), 843-852.

10. Václav, U., Jonáš, P., Mazur, O., 2007. Control of a Channel-flow Behind a Backward-facing Step by Suction/blowing, International Journal of Heat and Fluid Flow 28(4), 665-672.

11. Velazquez, A., Arias, J.R., Mendez, B., 2008. Laminer Heat Transfer Enhancement Downstream of a Backward Facing Step by Using a Pulsating Flow, International Journal of Heat and Mass Transfer, 51(7-8), 2075-2089.

12. Valencia, A., Hinojosa, L., 1997. Numerical Solutions of Pulsating Flow and Heat Transfer Characteristics in a Channel with a BackwardFacing Step, Heat and Mass Transfer, 32(3), 143-148.

13. Khanafer, K., Al-Azmi, B., Al-Shammari, A., Pop, L., 2008. Mixed Convection Analysis of Laminer Pulsating Flow and Heat Transfer Over a Backward-facing Step, International 
Journal of Heat and Mass Transfer 51(25-26), 5785-5793.

14. Tihon, J., Pěnkavová, V., Pantzali, M., 2010. The Effect of Inlet Pulsations on the Backward-facing Step Flow, European Journal of Mechanics-B/Fluids, 29(3), 224-235.

15. Selimefendigil, F., Öztop, H.F., 2017. Forced Convection and Thermal Predictions of Pulsating Nanofluid Flow Over a Backward Facing Step with a Corrugated Bottom Wall, International Journal of Heat and Mass Transfer, 110, 231-247.

16. Abbassi, H., Ben Nassrallah, S., 2007. MHD Flow and Heat Transfer in a Backward-facing Step, International Communications in Heat and Mass Transfer, 34(2), 231-237.

17. Selimefendigil, F., Öztop, H.F., 2015. Influence of Inclination Angle of Magnetic Field on Mixed Convection of Nanofluid Flow Over a Backward Facing Step and Entropy Generation, Advanced Powder Technology 26(6), 1663-1675.

18. Kumar, A., Amit K.D., 2012. Effect of a Circular Cylinder on Separated Forced Convection at a Backward-facing Step, International Journal of Thermal Sciences, 52, 176-185.

19. Suzuki, H., Kida, S., Nakamae, T., Suzuki, K., 1991. Flow and Heat Transfer Over a Backward-facing Step with a Cylinder Mounted Near its Top Corner, International Journal of Heat and Fluid Flow 12(4), 353-359.

20. Selimefendigil, F., Öztop, H.F., 2015. Numerical Investigation and Reduced Order Model of Mixed Convection at a Backward Facing Step with a Rotating Cylinder Subjected to Nanofluid, Computers \& Fluids 109, 27-37.

21. Selimefendigil, F., Öztop, H.F., 2014. Effect of a Rotating Cylinder in Forced Convection of Ferrofluid Over a Backward Facing Step, International Journal of Heat and Mass Transfer, 71, 142-148.

22. Edward, C., Lien, F.S., 2005. Permeability Effects of Turbulent Flow Through a Porous Insert in a Backward-facing-step Channel, Transport in Porous Media, 59(1), 47-71.

23. Benard, N., Sujar Garrido, P., Bonnet, J.P., Moreau, E., 2016. Control of the Coherent Structure Dynamics Downstream of a
Backward Facing Step by DBD Plasma Actuator, International Journal of Heat and Fluid Flow, 61, 158-173.

24. Ruisi, R., Zare-Behtash, H., Kontis, K., Erfani, R., 2016. Active Flow Control Over a Backward-facing Step Using Plasma Actuation, Acta Astronautica, 126, 354-363.

25. Garrido, P.S., Benard, N., Moreau, E., Bonnet, J.P., 2015. Dielectric Barrier Discharge Plasma Actuator to Control Turbulent Flow Downstream of a Backward-facing Step, Experiments in Fluids, 56(4), 70.

26. Gholamhosein, P.S., Mirzaei, M., Hajipour, M., 2015. Experimental Study of Separation Bubble Control Behind a Backward-facing step Using Plasma Actuators, Acta Mechanica 226(4), 1153-1165.

27. D'Adamo, J., Roberto, S., Artana, G., 2014. Active Control of a Backward Facing Step Flow with Plasma Actuators, Journal of Fluids Engineering, 136(12).

28. Kyoji, I., Nakamura, K., Senda, M., 2004. Heat Transfer Control of a Backward-facing Step Flow in a Duct by Means of Miniature Electromagnetic Actuators, International Journal of Heat and Fluid Flow, 25(5), 711720.

29. Brinkman, H.C., 1952. The Viscosity of Concentrated Suspensions and Solutions, J. Chem. Phys. 20, 571.

30. Society, T.R., Transactions, P., Society, R., Papers, C., Character, P., 1904. XII. Colours in Metal Glasses and in Metallic Films, Philos. Trans. R. Soc. London. Ser. A, Contain. Pap. a Math. or Phys. Character, 203, 385-420.

31. Sheikholeslami, M., Gorji-Bandpay, M., Ganji, D.D., 2012. Magnetic Field Effects on Natural Convection Around a Horizontal Circular Cylinder Inside a Square Enclosure Filled with Nanofluid, Int. Commun. Heat Mass Transf. 39, 978-986. 
